\title{
Sísmica de reflexão para prospecção de corpos hídricos subterrâneos em Montecarlo, Lucca, Toscana, Itália
}

\author{
Oziel S. Araújo ${ }^{1,3 *}$; Francesco Fiera ${ }^{2}$; Taís R. Zanato ${ }^{3}$; Marcus V.A.G. Lima ${ }^{3}$ \\ 1 - Università di Pisa \\ 2 - Geo-Energizers s.n.c - Pesquisas Sísmicas \\ 3 - Universidade Federal do Pampa
}

Copyright 2014, SBGf - Sociedade Brasileira de Geofísica

Este texto foi preparado para a apresentação no VI Simpósio Brasileiro de Geofísica, Porto Alegre, 14 a 16 de outubro de 2014. Seu conteúdo foi revisado pelo Comitê Técnico do VI SimBGt, mas não necessariamente representa a opinião da SBGf ou de seus associados. É proibida a reprodução total ou parcial deste material para propósitos comerciais sem prévia autorização da SBGf.

\section{Abstract}

This present study brings as the results of a seismic reflection inquiry performed in order to identify the possible levels of gravel, containing groundwater, to internal sedimentary shapes prevalently clayey. While the classical methods of geophysical prospecting, among which seismic refraction and MASW (Multichannel Analysis of Surface Waves), show us a scarce precision of details with increased depth, and the well log is very expensive in economics terms, the technique of reflection refunds a high detail of stratigraphic subsoil and is relatively fast in acquisition of campaign. For this reason, the research goals, was decided to operate a stretching seismic reflection, with alignment fixed and energization in each spacing interval between geophones, more two shots in the extremes, connected in an elaboration refraction tomographic of the same lines for statics corrections.

\section{Introdução}

A água é, sem dúvida, o nosso recurso mineral mais valioso. A demanda crescente da população mundial por água potável, combinada ao consumo industrial cada vez maior, tem alavancado a exploração de águas subterrâneas. A avaliação dos recursos hídricos se tornou, então, um dos maiores desafios da geofísica.

O levantamento sísmico de reflexão é a técnica geofísica mais utilizada e bem conhecida. Embora o estágio atual de sofisticação da técnica é, em grande parte, o resultado de um enorme investimento feito pela indústria de hidrocarboneto, a utilização deste método para estudos mais rasos, como os requeridos pela geologia de engenharia, é o que tem os popularizado, pois de fato, nos últimos anos os chamados levantamentos sísmicos de reflexão assumiram grande notoriedade ao serem usados cada vez mais no delineamento de superfícies geológicas rasas (KEAREY, et al 2002).
A área de investigação está localizada nas proximidades de Lucca, pequena província da Região da Toscana, mais especificamente no município de Montecarlo território no qual se desenvolve no contexto sub-Apeninos da Itália Central (Figura 1).

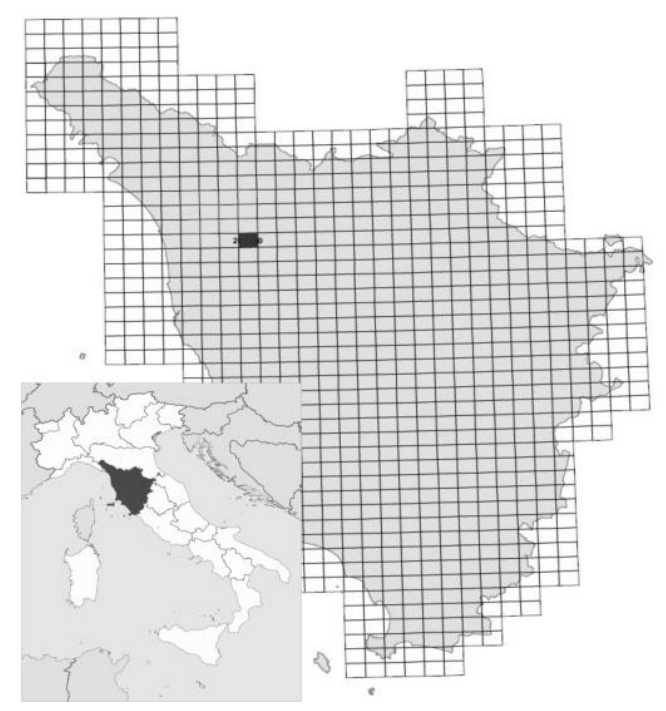

Figura 1 - Enquadramento cartográfico da área de estudo.

A estrutura geológica e geomorfológica sob uma escala regional da área é o resultado de uma série de eventos tectônicos de idades pliocênica-quaternária. Como resultado da tectônica distensiva que afetou parte do Apenino Setentrional foram formadas depressões tectônicas entre as quais se desenvolveram bacias lacustres antigas. 
A mesma tectônica distensiva caracteriza uma depressão delimitada pelo Monte Pisano a Oeste, pelo Monte Albano a Leste e pelos relevos dos Pizzorne ao Norte (depressão de Lucca-Montecarlo-Vinci) que representa a continuação do mesmo evento estrutural da baixa, média e alta Garfagnana e que se estende até o Sul na Val d'Era e na Val d'Elsa (TREVISAN \& alii, 1971).

$\mathrm{Na}$ ampla bacia foram diferenciados dois dos diversos eventos de sedimentação com depósitos marinhos e salobros. Ao Sul foram depósitos finos até a linha que une San Ginese-Vinci; ao Norte de tais linhas hipotéticas os depósitos são do tipo continentais. A linha de separação entre os dois contextos sedimentares corresponde provavelmente a depósitos dunares. Os sedimentos da depressão de Lucca Montecatini - Vinci pertencentes a um primeiro ciclo lacustre são constituídos de argila cinza com linhitos, argila arenosa e areias com níveis de seixos a elementos prevalecentes do "Verrucano" (Figura 2).

Sobre tais depósitos, o fechamento do ciclo lacustre, foram agradados sedimentos de um ciclo fluvial e fluvial-lacustre compreendendo conglomerados e seixos avermelhados a elementos prevalecentes do Verrucano, em escassa matriz arenosa contendo na parte baixa seixos em abundante matriz argilosa (NARDI \& alii, 1987).

Esses depósitos foram, em seguida, afetados por uma fase de levantamento e "tilting" sentido E-SE, provavelmente induzido do aumento da dorsal Montecarlo-Cerbaie. Em discordância angular, nos depósitos lacustres e fluvial-lacustres se encontram, enfim, os sedimentos aluvionais recentes. À escala de detalhe, a zona de intervenção se coloca a uma cota média de cerca $45 \mathrm{~m}$ a.n.m (acima do nível do mar), em um contexto morfológico sopé, com lado degradante sentido Sul-Oeste, em direção à planície aluvional de Lucca. Em superfície, está presente um depósito de idade compreendida entre o Rusciniano superior (3 Ma) e o Villafranchiano superior (1,3 Ma) agradado em ambiente deposicional lacustre. Os sedimentos são constituídos de argila cinza com linhito, argila arenosa e areia com níveis de seixos a elementos prevalecentes del Verrucano (TREVISAN \& alii, 1971).

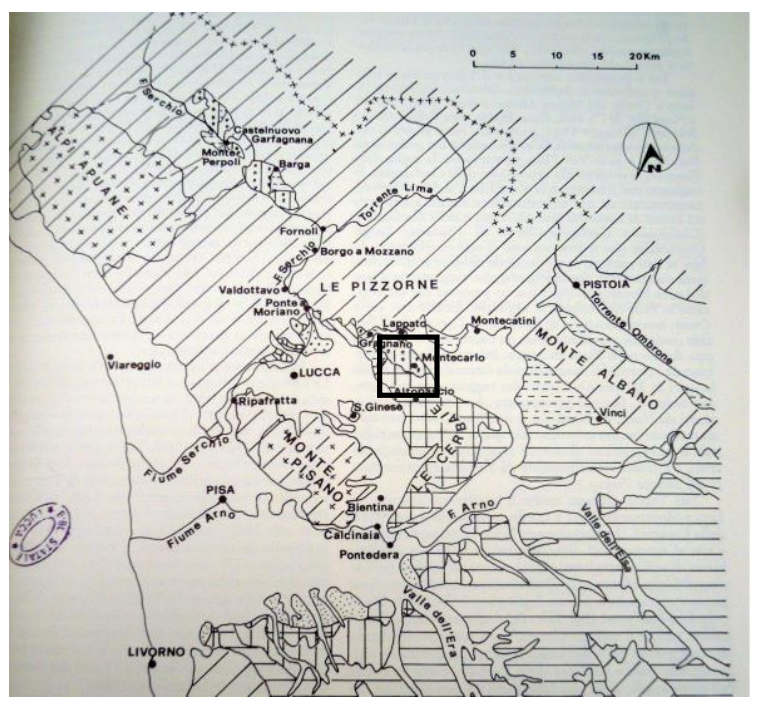

Figura 2 - Enquadramento geológico regional (adaptado da Carta geológica da Planície de Lucca Marco Scarpellon, 2012).

$\begin{array}{ll}+ & \begin{array}{l}\text { Depósitos lacustres e fluvial- } \\ \text { deltáicos pleistocênicos }\end{array} \\ \text { Conglomerados, seixos e areias }\end{array}$

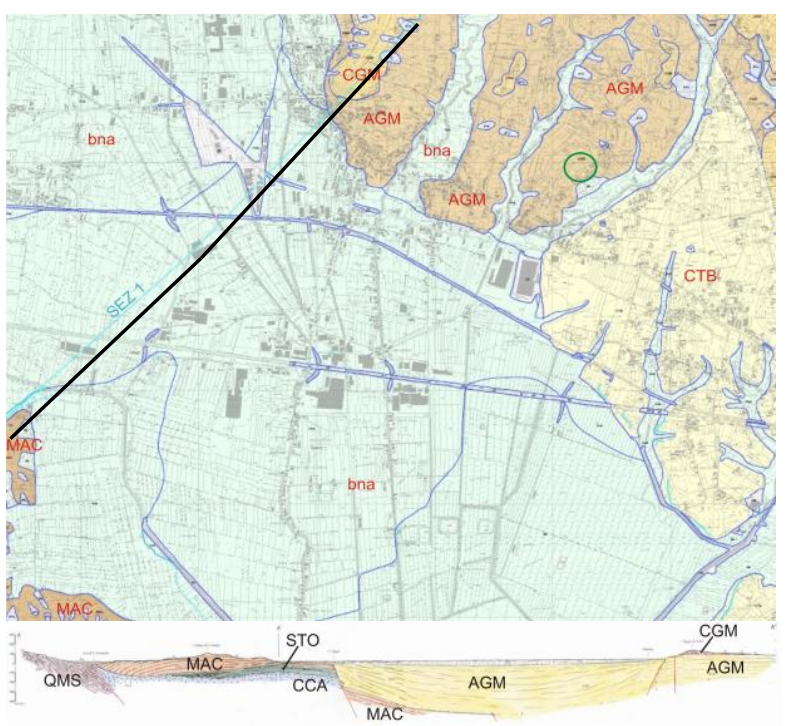

Figura 3 - Carta Geológica (Projeto CARG - Região Toscana). QMS: Quarzitos do M. Serra (quarzitos, metarenitos, siltitos); CCA: Calcário Cavernoso (calcá dolomíticosi); STO: Scaglia Toscana (argilitos e argilitos siltosos) MAC: Macigno (arenitos turbidíticos); AGM: Argilas de MarginoneMastromarco (argilas arenosas com linhitos e com níveis de cascalhos; CGM: Conglomerado de Montecarlo (seixos e cascalhos arredondados em matriz arenosa); CTB: Formação das Cerbaie (cascalhos e areia em matriz argilosa; bna: depósitos aluvionais recentes; círculo verde: localização da pesquisa. 


\section{Problema Investigado}

Para a aquisição dos dados que permitiram a reconstrução do modelo estratigráfico do subsolo foi utilizado um sismógrafo de 24 canais. Aos canais de registro foram ligados grupos de 2 geofones com frequência central de $100 \mathrm{~Hz}$ dispostos no alinhamento sísmico com uma distância de 5,0 m entre geofones. Fonte dos tiros, distribuídos em cada intervalo de geofones, mais dois aos extremos, foram efetuadas por um objeto de $54 \mathrm{~kg}$ em queda acelerada. A posição topográfica dos pontos de tiros e de registro foi detalhadamente medidas por meio de uma estação topográfica GPS e reproduzida em 2D em software CAD.

As linhas sísmicas foram adquiridas com uma frequência de amostragem de $10.000 \mathrm{~Hz}$, por uma duração de 0,5 segundo, sem a aplicação de ganho. Em fase de elaboração, depois das operações obrigatórias de Quality Control, recuperação das amplitudes e muting das primeiras chegadas, foi aplicada a deconvolução preditiva para eliminação das reflexões de múltiplas seguida de uma deconvolução spike para obter um incremento no detalhe do sinal. Nas fases seguintes foram aplicados: filtro passa banda com frequências de 25 e $130 \mathrm{~Hz}$, branqueamento espectral e correção estática das linhas ao datum de referência, posto à cota máxima do perfil topográfico.

Depois de uma análise atenta dos espectros de velocidade, calculados nos agrupamentos individuais de CMP foi realizado um modelo 2D para correções de NMO e a realização de uma primeira seção stack. Nas fases sucessivas foram efetuadas operações de melhoramento do sinal que levaram à definição da seção stack definitiva.
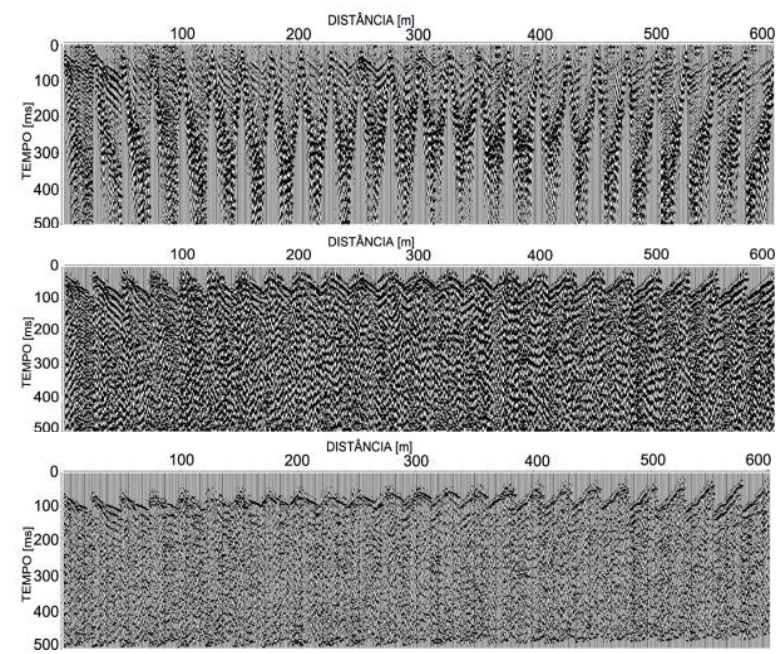

Figura 4 -.Detalhe dos shot gathers adquiridos

Para uma melhor definição do modelo superficial de velocidade foi também efetuada a modelagem inversa a partir elaboração da técnica da tomografia sísmica de refração. $\mathrm{O}$ modelo $2 \mathrm{D}$ de detalhe resultante foi usado para correções residuais estáticas e para a migração da seção sísmica, seja no domínio do tempo, e também em termos da profundidade (Figura 5).

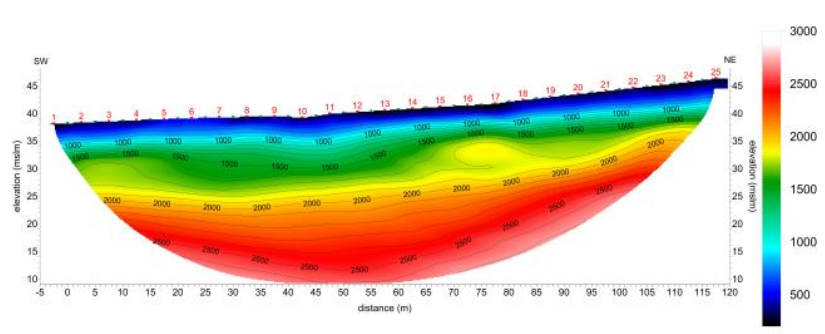

Figura 5 -.Tomografia sísmica de refração.

\section{Resultados}

Os dados obtidos a partir do levantamento sísmico de reflexão evidenciaram a presença de dois importantes refletores próximos à superfície, separados entre si, a uma profundidade entre os 30 e os $100 \mathrm{~m}$ ao longo da seção sísmica e várias outras reflexões a profundidades maiores.

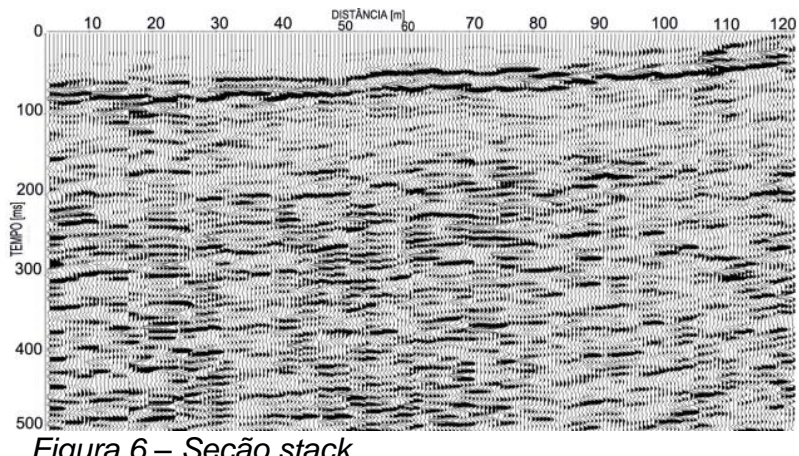

Como se observa na Figura 6, as reflexões não são contínuas, mas se interrompem a traços, têm intensidade e pendência variável e andamento flutuante.

A posição estratigráfica, a orientação e disposição destes níveis são compatíveis com os níveis de cascalhos presentes ao interno da litologia AGM supracitada. Essas hipóteses são fundamentadas pela presença de uma estratigrafia de poço na área, localizado algumas centenas de metros a oeste do alinhamento sísmico, que atesta a presença de um importante nível de cascalho em camadas à profundidade de $71,0 \mathrm{~m}$ do perfil sísmico. A estratigrafia de detalhe do poço, indicado na Figura 7 como P1, vem apresentada na Tabela 1 e 2:

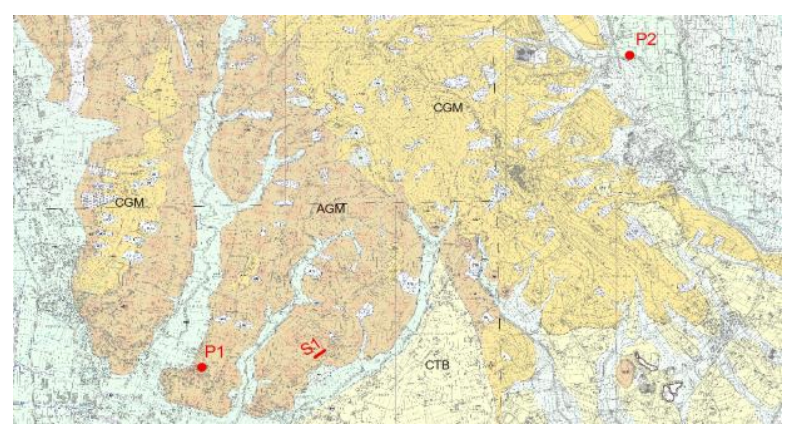

Figura 7 - Localização do levantamento sísmico e poço de referência. 
TABELA 1 - Estratigrafia do Poço P1 (localização na

\begin{tabular}{c|c|c|c|c}
\multicolumn{5}{c}{ Figura 7) } \\
\hline Estrato & $\begin{array}{c}\text { de } \\
(\mathbf{m})\end{array}$ & $\begin{array}{c}\text { até } \\
(\mathbf{m})\end{array}$ & espessura & litologia \\
\hline 1 & 0.0 & 0.5 & 0.5 & solo vegetal \\
\hline 2 & 0.5 & 7.8 & 7.3 & argila arenosa \\
\hline 3 & 7.8 & 35.0 & 27.2 & argila \\
\hline 4 & 35.0 & 35.8 & 0.8 & argila arenosa \\
\hline 5 & 35.8 & 71.0 & 35.2 & argila \\
\hline 6 & 71.0 & 75.0 & 4.0 & $\begin{array}{c}\text { areia e } \\
\text { cascalho }\end{array}$ \\
\hline 7 & 75.0 & 80.0 & 5.0 & argila
\end{tabular}

TABELA 2 - Estratigrafia do Poço P2 (localização na

\begin{tabular}{c|c|c|c|c}
\multicolumn{5}{c}{ Figura 7) } \\
\hline Estrato & $\begin{array}{c}\mathbf{d e} \\
(\mathbf{m})\end{array}$ & $\begin{array}{c}\text { até } \\
(\mathbf{m})\end{array}$ & espessura & litologia \\
\hline 1 & 0.0 & 15.0 & 15.0 & argila arenosa \\
\hline 2 & 15.0 & 25.0 & 10.0 & $\begin{array}{c}\text { areia e } \\
\text { cascalho }\end{array}$ \\
\hline 3 & 25.0 & 115.0 & 90.0 & $\begin{array}{c}\text { argila com } \\
\text { cascalho }\end{array}$ \\
\hline 4 & $\begin{array}{c}115 . \\
0\end{array}$ & 124.0 & 9.0 & $\begin{array}{c}\text { areia e } \\
\text { cascalho }\end{array}$ \\
\hline 5 & $\begin{array}{c}124 . \\
0\end{array}$ & 139.0 & 15.0 & arenitos
\end{tabular}

Com base no contexto geológico, dos resultados obtidos do levantamento sísmico de reflexão e da estratigrafia de poço acima relatada, foi possível reconstruir a estratigrafia da seção do subsolo investigado.
A seção geológica da Figura 8 ilustra uma sedimentação de facies fluvial-lacustre onde a litologia principal é constituída de argila e argila arenosa bem consolidada $(V p \approx 2000 \div 2500 \mathrm{~m} / \mathrm{s})$, no qual internamente se desenvolveram paleocanais representados por cascalho e areias prevalecentes.

$\mathrm{Na}$ porção mais profunda da seção sísmica, de 150$200 \mathrm{~m}$, é muito provavelmente devido à Formação do Macigno que aparece numa estratigrafia de poço (colocada no lado setentrional da Colina de Montecarlo) à profundidade de cerca $124 \mathrm{~m}$ do plano de campanha (cota do plano de campanha do poço P2 cerca de $25 \mathrm{~m}$ a.n.m.).

Da documentação ligada à estratigrafia do poço P1 é sabido que o nível de cascalho e areia interceptados é capaz de acomodar um aquífero artesiano moderadamente produtivo. A partir disso, pode-se inferir que os domínios de cascalhos caracterizados na porção central do perfil sísmico são, por consequência, capazes de acomodar um aquífero potencialmente produtivo.

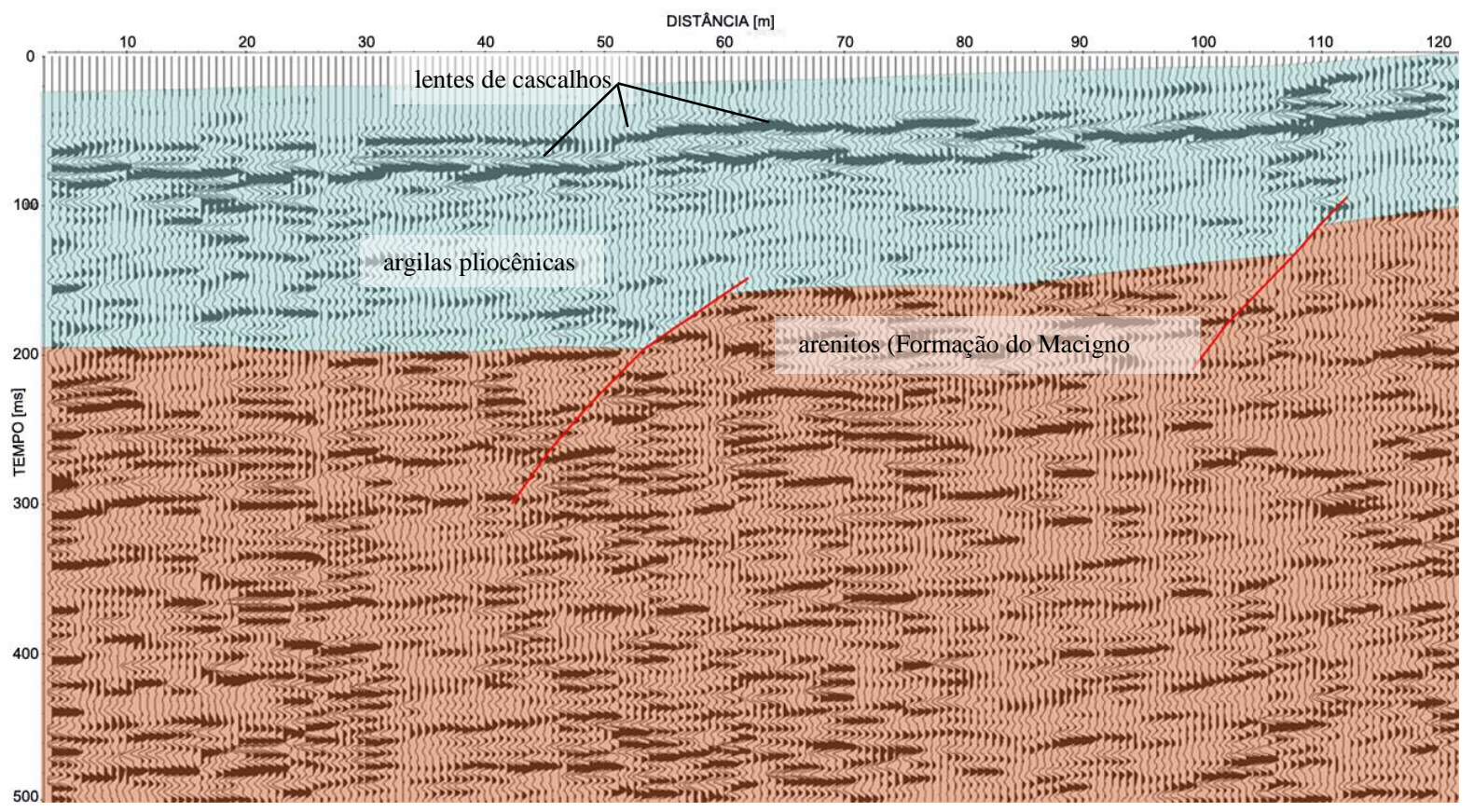

Figura 8-.Seção stack interpretada 


\section{Discussão e Conclusões}

O levantamento sísmico de reflexão, realizado na Toscana Centro-Setentrional, demonstrou que a aquisição dos dados sísmicos utilizando um sismógrafo de 24 canais, geofones de $100 \mathrm{~Hz}$ e quedas de peso como fontes sísmicas; pode ser um eficiente instrumento para a identificação de corpos hídricos em cascalhos imersos em depósitos sedimentares principalmente argilosos.

Apesar do processamento de dados ser relativamente complexa, requer, na maioria dos casos, apenas de ferramentas básicas como: filtro passa-banda ou F-K, recuperação das amplitudes, correção de NMO e stacking das linhas sísmicas. O fato de não se utilizar fontes de energia de elevada intensidade, limita a profundidade de investigação, todavia, esta metodologia de pesquisa geofísica pode ser usada para localizar, delinear e identificar a disposição dos diversos tipos de sedimentos no subsolo, e então constituir uma ferramenta econômica e eficaz para a prospecção hidrogeológica.

Por fim, utilizando fontes a elevada frequência e espaçamento entre os geofones sendo inferior a 1,0 m, é possível adicionar uma ótima resolução também em sedimentos de xistos próximos à superfície, fazendo com que o método torne mais eficaz o georadar, este fortemente limitado na presença de umidade no subsolo e dos terrenos de elevada resistividade.

\section{Agradecimentos}

À Sociedade Brasileira de Geofísica - SBGf, pela oportunidade de apresentação do presente trabalho.

À Coordenação de Aperfeiçoamento de Pessoal de Nível Superior (CAPES) pela concessão da bolsa de estudos graduação sanduíche, Ciências Sem Fronteiras.

E um agradecimento especial à Geo-Energizers s.n.c - Pesquisas Sísmicas na pessoa do geofísico Francesco Fiera pela grande contribuição, paciência, e seus ensinamentos em campo e pós-campo para elaboração deste trabalho. Grazie mille!

\section{Referências}

Trevisan L., Brandi G. P., Dallan L., Nardi R., Raggi G., Rau A., Squarci P., Taffi L., Tongiorgi M., 1971. Note illustrative della Carta Geologica d'Italia alla scala 1:100.000:foglio 105 (Lucca). Min. Ind., Comm., Artig., Roma.

Nardi R. , Nolledi G. \& Rossi F., 1987. Geology and Hydrogeology of the Lucca plain - Geogr. Fis. Dinam. Quat., 10, 132-160, $12 \mathrm{ff}$, 1 tab., 1 appendice, $3 \mathrm{tt}$.

Marco Scarpellon, 2012. Piana di Lucca - Wikipedia, l'enciclopedia libera.

KEAREY, Philip; BROOKS, Michel; HILL, Ian. Geofísica de Exploração. São Paulo, 2002.
Turner, F. J. \& Werhoogen, J., 1960. Igneous and metamorphic petrology. 2nd ed., McGraw Hill, New York, USA. 